\title{
From the Desk of the Executive Editor
}

This peer reviewed journal is an important assortment of different articles related to various disciplines of medical and allied sciences.It welcomes original articles,review articles,meta analysis, systemic reviews and case report from physicians and allied professionals of different medical/scientific institutions from home and abroad.The website of the journal (www.birdemmedj.org)can be browsed conveniently and the journal can be viewed on line through Googles and Yahoo. It,s ISSN is print :23053712, Online:2305-3720. We have received official registration for the journal from Bangladesh Medical and Dental Council(BMDC).It has also been enrolled to BanglaJoL.One can browse articles by searching the title.Manuscript can now be submitted online.We can enumerate the online readers.Needless to say ,the statistics is very much encouraging and enthusiastic.

The number of original articles have already been increased.The journal is now published in every 4th month instead of previous 6th month.These all proves endorsement of quality,timely publication and fair peer review process of the journal.In this issue we highlighted 'doctor patient relationship ' which is part and parcel of good medical practice as editorial.

We feel tremendously buoyed by our readers participation and their responses from all over the globe.We are very much thankful to the online readers. We also express our pristine appreciation and gratefulness to the authors who bolstar our hope immensely and enrich the journal aptly with valuable articles. The editorial board and the advisory boards are eagerly looking forward to your valuable advise,suggestions and recommendation in future. With very much appreciation to our authors, who encourage us and enrich the journal with articles of variations, waiting eagerly for newer articles.

Thanks

Professor Dr. Khwaja Nazim Uddin 